\title{
Design for Sustainability \& Product Differentiation An Empirical Study at SALSAL factory for Purified Water
}

\author{
Abdul Salam Ibrahim Obeyed ${ }^{1}$, Hamid Shakir Mahmoud ${ }^{2}$ \\ \{abdulsalam.abrahem@stu.edu.iq ${ }^{1}$,h.s.mhmood@stu.edu.iq ${ }^{2}$ \} \\ Technical College of Management Basra, Southern Technical University ${ }^{1,2}$
}

\begin{abstract}
This research aims to analyse and investigate the impact of design for sustainability (D4S) in terms of all three components of sustainability (economy, environment, and society) on product competitiveness in term of cost, quality, flexibility, and delivery. The main questions of this research focus are: how can design for sustainability affect product differentiation? The importance of this research is to focus on the new interest of literatures on sustainability which represent the a critical and strategic challenge for business organizations. Sustainability becomes the most source of competitive advantage in current business environment. method is useful in comparing various competitive products of the same family. This technique uses a visual representation of PSI to give an overview of the product's inherent and built-in sustainability levels in a simple and effective manner. The results of this paper improve our hypotheses related to the interactive roles of (PLS) stages with (PSI) (Social, environmental, and economic) .
\end{abstract}

Keywords: Design for Sustainability (D4S), Product Differentiation (PD).

\section{Introduction}

Contemporary literature in the field of production and operations management has shown a growing interest in the challenges facing traditional product design systems, specifically the challenges of integrating sustainability with design and manufacturing systems at the product and process levels. The subject of Design for Sustainability has received great attention in many contemporary studies and knowledge contributions. Due to the shift in the logic of competition from economies of scale and cost advantages towards sustainability and the advantages of flexibility and acceleration in response to the rapid changes in the industry environment. Several studies confirmed that design for sustainability means considering environmental, social and economic considerations in the initial stages of design, which will have positive effects in improving the competitiveness of the product. The research problem was represented in the question: How can design for sustainability contribute to improving the competitiveness of the product in the field of achieving the advantages of flexibility, cost, delivery, and cost domestically? The research sample included a comprehensive survey of all workers in the factory, including engineers and administrators, whose number (20) was distributed to a questionnaire that was developed and tested for its validity and stability using many statistical measures. The research included four sections, the first section was devoted to the research methodology and previous studies, while the second section was devoted to presenting and 
discussing contemporary knowledge contributions in the field of design for sustainability and product competitiveness.

\section{Research Methodology}

The first section of the research was devoted to presenting the paragraphs of the approved methodology, the most important of which is the research problem, questions, objectives, and importance, as well as the research model and hypotheses, data collection tool, and statistical analysis methods. The following is a brief discussion of the research methodology paragraphs:

\subsection{Problem Statement and Questions}

According to the researcher's review of the literature related to design for sustainability, which showed that business organizations face great challenges as a result of growing competition and acceleration in providing designs that have the ability to respond to changes in the needs and desires of customers, as well as the transformation of sources of competitive advantage from cost advantages and economies of scale to advantages of creativity, flexibility and economics The scope, as Design for Sustainability (D4S) has become one of the most prominent methodologies that have achieved great successes in activating the ability of organizations to achieve flexibility and rapid response to the rapid changes in the industry environment and market dynamics to ensure the improvement of product competitiveness and an important source for strengthening the capabilities of adaptation and strategic creativity and based on the results of field coexistence with the reality The product design activities in the laboratory under research and the results of unstructured interviews conducted with workers in the field of design, research and development $* *$ The research problem was formulated and developed according to the following questions:

1. What is the role of the Design for Sustainability (D4S) approach in achieving product competitiveness?

2. Does the management of the laboratory under consideration have a clear vision of the design methodology for sustainability and its role in activating the competitiveness of the product? To what extent does it adopt that methodology as a competitive advantage?

3. What are the dimensions of the requirements for implementing the design methodology for sustainability in the laboratory under investigation?

4. What are the requirements to achieve product competitiveness in the laboratory under investigation?

5. How does the Design for Sustainability methodology contribute to activating the research organization's ability to achieve product innovations and improve its competitiveness?

\subsection{Research Objectives}

The research seeks to achieve the following main objectives:

1. Presentation and discussion of contemporary knowledge contributions related to Design for Sustainability 
2. Presentation and discussion of contemporary knowledge contributions related to product competitiveness

3. Analyse and diagnose the role of the Design for Sustainability methodology in improving product competitiveness

4. Diagnosing the reality of the Design for Sustainability methodology and its requirements in the research organization

5. Analysis of the reality and indicators of product competitiveness in the research organization

6. Presenting recommendations and proposals that contribute to strengthening the capacity of the organization under consideration by activating the requirements for successfully implementing the Design for Sustainability methodology to improve its competitiveness by improving product competitiveness

7. Testing the correlation between the Design for Sustainability methodology and product competitiveness

8. Testing the relationship between the design for sustainability methodology and product competitiveness.

\subsection{Proposed Conceptual Model}

Contemporary literature has shown an accelerated interest in the design methodology for sustainability as one of the contemporary strategies in strengthening the ability of business organizations to improve their competitiveness, not in the field of creativity in developing new products and processes, but in creating a balance between the advantages of cost, quality, recommendation, and sustainability, which contributes to improving the flexibility and speed of the organization's response to changes in Industry environment and hence the importance of the research are represented in two dimensions, the first is theoretical. For sustainability in the organization under discussion and its role in improving and activating the competitiveness of the product, as well as providing suggestions and recommendations that contribute to improving the organization's ability to employ the design methodology for sustainability in improving the competitiveness of its products.

\subsection{Theoretical Research Model}

Considering the theoretical trends of the study, which are based on the opinions of a group of researchers and their field implications, a hypothetical research model was formulated that identifies the most important relationships and influences between the variables addressed in the research. It was based on two types of variables, which are as follows:

The independent variable, which represents the Design for Sustainability methodology, whose study includes the adoption of a set of work stages that express its role as an independent variable in the hypothetical scheme of the research. Design for sustainability includes three dimensions: the environmental dimension of design, the economic dimension of design, and the social dimension of design, according to the Triple Bottom Line model. The variable adopted in the research hypothesis is (Dependent Variable).

This is represented by the product competitiveness variable, which was measured according to the model (Pasi Ojala, 2004) and considering the following indicators:

1. Cost competitiveness: It is measured by the ability of the company's products to compete with the cost advantage. 
2. Quality competitiveness: It is measured by the product's ability to achieve quality advantages or quality competitiveness

3. Competitive flexibility: It is measured by the product's ability to achieve diversity and respond to changes in customers' tastes.

4. Competitive delivery: It is measured by the organization's ability to achieve the advantages of on-time delivery. Fig 1 shows the hypothesis of the research:

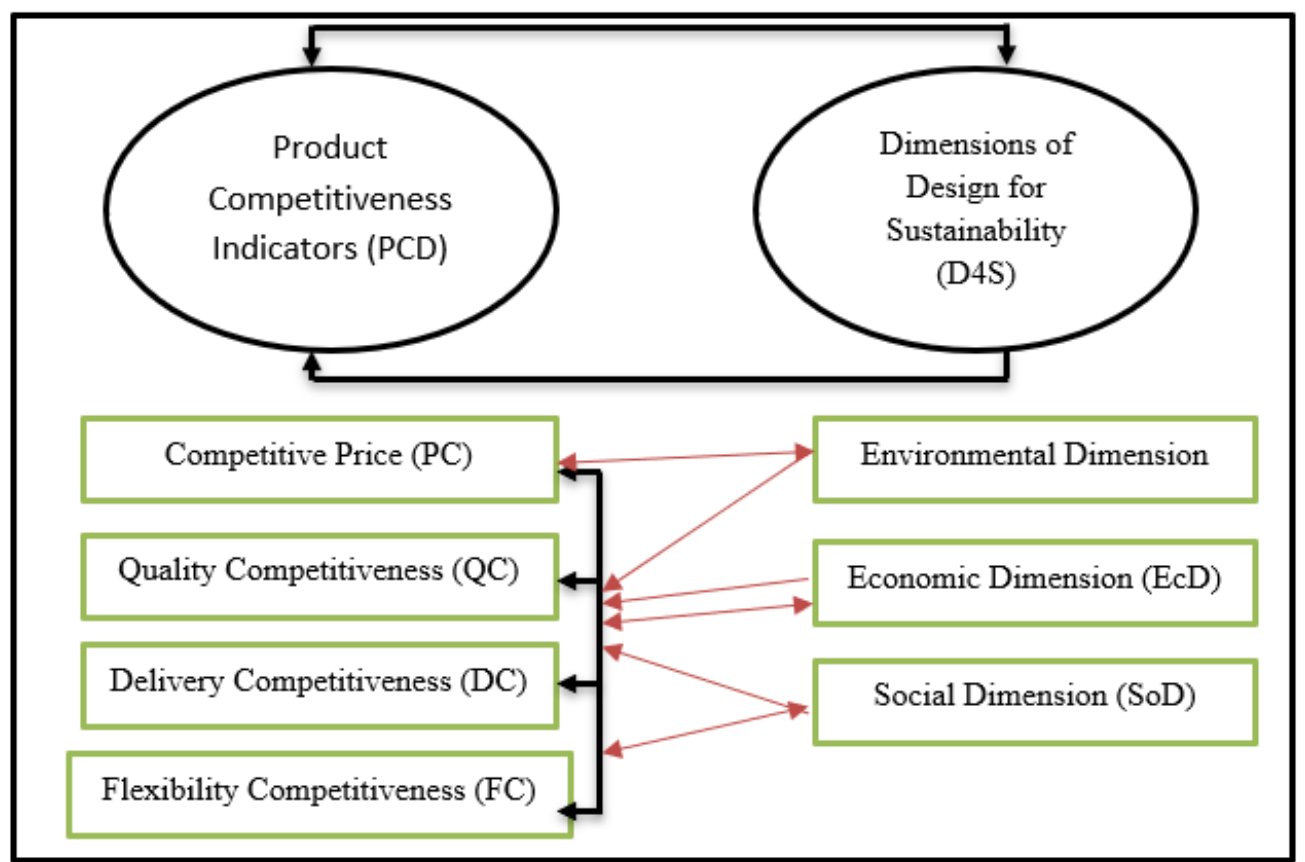

Fig 1. The hypothesis of the research.

\subsection{The Following Hypotheses were Tested}

H1: A statistically significant correlation between the objectivity of sustainability and product competitiveness, from which the following sub-hypotheses are derived:

H11: a statistically significant correlation, the environmental dimension of the design methodology for sustainability and product competitiveness

H12: a statistically significant correlation, the economic dimension of a methodology for sustainability and product competitiveness

H13: a statistically significant correlation with the social dimension of the design methodology for sustainability and product competitiveness

$\mathrm{H} 2$ : The variance in the product can be explained in terms of dimensions of sustainability.

$\mathrm{H} 21$ : The variance in who the product is for can be explained in terms of the environmental dimension

H22: The discrepancy can be explained by whom it is produced for

$\mathrm{H} 23$ : The discrepancy in who the product is for can be explained in terms of the social dimension for sustainability. 


\subsection{Study Borders}

The limits of the study were as follows:

1. Place Boundaries: The researcher elected Salsil Mineral Water Factory in Basra as a field to test hypotheses and a model as one of the organizations facing severe competition in the field of design and production through the availability of competing products in the local markets. Governorate.

2. Time Borders: The research period was determined by the period from (1/7/2018) to (1/9/2017), as this period was sufficient for the process of distributing and collecting the questionnaire and conducting many unstructured interviews with department managers and officials of different units to collect the necessary information about the reality of the situation. Study variables in the laboratory under study.

3. Conceptual Borders: The intellectual treatments of the topic of research extend to the field of production and operations management, specifically in the fields of design for sustainability and creative design, as they are among the emerging topics that have received noticeable interest from researchers and practitioners in the recent period.

\subsection{Research Field and Data Collection}

The Silsil Laboratory, which specializes in the production and filling of filtered and sterilized water with ozone, was selected. The laboratory holds standard specifications from specialized laboratories and the ISO (9000) certificate. It was established in 2009. The goal of the laboratory is to develop national products and compete with local and foreign products. The laboratory has a specialized staff of engineers and technicians, and the number of workers in the laboratory (60) workers, as the factory produces three sizes of water bottles, large and medium, and a small mug. To implement the research methodology, several methods were employed in obtaining data and information. The available references, periodicals, and the Internet were used to cover the theoretical aspect. While the questionnaire was adopted in the practical aspect, which was considered the main means, as its paragraphs were formulated in line with the research variables by taking advantage of the literature that dealt with these two variables. Simplicity and clarity were considered in drafting the questionnaire's paragraphs, as well as subjecting it to scientific and objective tests to measure its stability and apparent sincerity. Consistency) in terms of Cronbach's alpha, as the value of the tested coefficient for all paragraphs of the questionnaire was $(0.76 \alpha)$, which is greater than the standard value of the scale of $(0.7)$, which confirms the acceptance of the level of internal consistency of the measurement tool as well as the significance of the correlations between the paragraphs of the tool measurement.

\section{Intellectual Framework}

The traditional approaches to product design and manufacturing are based on a set of product characteristics, including (functionality, performance, cost, time-to-market) and others. Contemporary literature in the new millennium has addressed many cognitive problems and challenges, including the integration between life-cycle data and design for sustainability. (D4S) for the product and process (Product / Process Sustainable) and its contents to provide innovative designs and products that contribute to improving the competitiveness of the product 
and its ability to achieve the added value of the customer. These techniques can be employed in the design of products of an industrial or consumer nature in small sizes and large diversity (low volumes and large varieties Hence, the upcoming design and manufacturing practices require industrial organizations to realize the contemporary changes and challenges to shift from those practices to technologies that achieve expanding the traditional life cycle ranges from the perspective of the multi-stage life cycle (multiple life-cycles) towards the product / exchanged materials cycle. Perpetual Product/Material Life). The premise of design for sustainability is to reduce emissions and outputs as the negative impacts on the environment by adopting skilful, sensitive design and that achieving this requires renewable resources, reducing environmental impacts, and linking workers to the natural environment. In addition to reducing negative impacts, sustainable design must generate meaningful creative projects that can change Behaviour. The dynamic balance between environmental and social concerns generates longterm relationships between the user and the service/product and finally considers the environmental and social differences. (M). The principle that all trends of progress run out, and terminate with diminishing returns, is evident in the typical ' $\mathrm{S}$ ' curve of the life cycle of technology and the useful life of any system as discussed in Industrial Environment and Life Cycle Assessment. Diminishing returns are the result of reaching normal limits. The common practice of business management is to read the diminishing returns in any direction of the effort as evidence of diminishing opportunities and the possibility of accelerating decline and an indication of the creation of new opportunities elsewhere.

Innovative design methodologies and innovative manufacturing techniques must be developed to create synchronization between traditional product characteristics and the life cycle to achieve the following basic objectives:

1. Reduction of manufacturing costs

2. Reduction of product development time

3. Reduction of material use

4. Reduction of energy consumption

5. Increased operational safety

6. Enhanced societal benefits

7. Reduction of industrial waste

8. Repair, reuse, recovery, and recycling of used products/materials

9. Consideration of environmental concerns

10. Education and training of the workforce

The accelerated transformations in the intellectual construction of the contemporary literature in the field of product design and manufacturing aim towards optimizing methodologies integrating environmental considerations, energy efficiency, product design, and manufacturing techniques for sustainability with product maintenance, reassembly, reuse of materials, remanufacturing, and recycling considerations. Contemporary design and manufacturing techniques have promoted new systems of thinking in the development of designing new products and processes and focused on the need to pay attention to the interests of all partners and stakeholders in the industry environment, which in turn requires the development of design methodologies, manufacturing processes, post-use processes, and resource planning systems ( ERP) to simultaneously achieve multiple goals, including factory profitability, the rapid launch of products to the market, and conservation of environmental resources in line with environmental considerations. 
Sustainability studies, in general, have shown a clear focus on the environmental, social, economic, and technical dimensions, including the problems of public health, community welfare, and the environment across the full business cycle, which is defined as the period from the start of the process of extracting and reducing raw materials to the complete product. Fig 2 shows the dimensions of design for sustainability with the presentation that most of the literature reviewed by the researcher agreed on three dimensions (environmental, social, and economic), while some knowledge contributions showed the technical dimension as the fourth dimension of sustainable design (Nagel, Pappas, and Olga Pierrakos) [1].

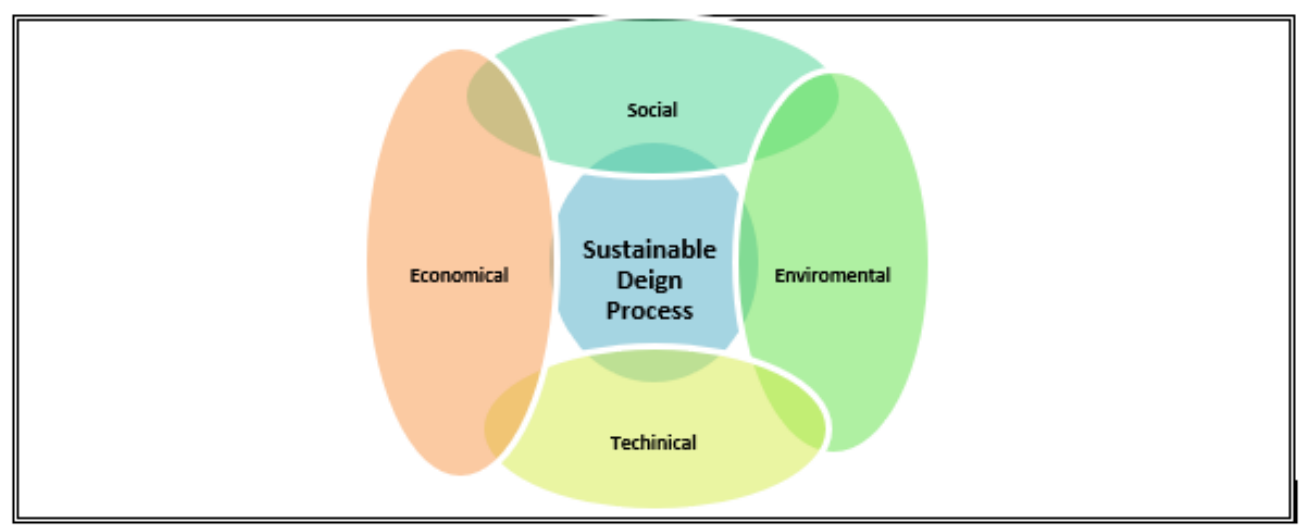

Fig 2. Integration of environmental, technical, social, and economic dimensions to generate sustainable design. Source: Robert L. Nagel, Eric C. Pappas, and Olga Pierrakos, 2012 "On a Vision to Educating Students in Sustainability and Design—-http://www.mdpi.com/journal/sustainability.PP: 72-91

As for sustainable products, they are generally defined as those products that achieve environmental, social, and economic benefits in conjunction with the protection of public health, welfare, and the environment during their total commercial life cycle, starting from the start of reducing materials and ending with the final product, taking into account the needs of future generations. Completely with nature throughout its entire life cycle[2]. . From a traditional perspective, the economic and environmental analysis of products usually focuses on analyzing the impact of these products on society. It is mostly a development to analyze the life cycle of an individual product, and that many other aspects, such as recycling in conjunction with multiple reuse opportunities, coincide with many economic, social, and environmental gains, which are The most important in contemporary manufacturing practices. The idea of recycling, reuse, and remanufacturing at present has come in conjunction with great interests in developing innovative manufacturing systems and processes in the field of products and materials to create products with multiple life cycles (Multiple). life-cycle products), which has become the reality in many applications in the fields of product manufacturing. The traditional concept that includes the study of the life of the product from cradle to grave ("from cradle to grave" has been transformed in the manufacturing literature to from cradle to cradle) from cradle to cradle") [3] and it is an important conceptual shift in the science of manufacturing, which has taken an important knowledge space at the level of the intellectual model of contemporary literature. This is due to environmental efficiency and concerns that coincided with reducing toxic emissions in air and water, and production with a minimum amount of waste, a minimum amount of energy, and at all levels. The literature in the past few years in the field of product and process sustainability has been concerned with attempts to develop 
methodologies for assessing and evaluating the level of sustainability in the various stages of the product life cycle, and that this type of evaluation has helped manufacturing organizations to explore unsustainable components and elements at any stage of the product life cycle. Many types of research and studies presented qualitative or descriptive results about the product life cycle, which confirmed the difficulty of quantifying the results of those stages $[3,4]$ and most of these studies are non-analytical and non-scientific in terms of the perceived value of their contributions. However, product sustainability does not mean or does not cover only simple assessment. The environment, as a measure of contribution, includes a comprehensive and simultaneous assessment of the environmental, economic, and social impact. These indicators are overlapping and interrelated and have an impact on each of the stages of the product life cycle with different levels of impact in the various stages. Legal legislation is also one of the most important factors motivating the manufacture of sustainable products. Among the international legislation in this regard is (i) Waste Electrical and Electronic Equipment (WEEE) legislation [6], (ii) legislation to reduce the use of hazardous materials (RoHS) [7], (iii) End-oflife-cycle legislation (ELVs) [8], which are legislation that aims to determine the responsibility of the extent to which products conform to specific sustainability goals across their life cycle directly, either to producers, manufacturers or exporters. As for the other incentives for the sustainability of the crown, they are represented in the positive social expectations and economic gains. In our current research, two scenarios will be adopted, the first includes the economic stimulus and the other social, both of which work within the framework of the environmental stimulus. The main objective of the research is to try to shed light on the importance of product design for sustainability by focusing on the real need to create sustainable products to achieve economic, social, and environmental benefits. The new framework for the comprehensive assessment of product sustainability will be presented in the research, and this new methodology includes the four stages of the product life cycle (before manufacturing, during manufacturing, during use, and after use) to cover the three components of sustainability (economic, environmental and social), all of which are integrated into an ordinal system to reach a scale Formulated for product sustainability:

\subsection{Total Life-Cycle of Manufactured Products - Four Stages:}

The industrial product life cycle includes four stages in the closed channel system (CLS):
a) Pre-manufacturing
b) Manufacturing
c) Use
d) Post-Use

\subsection{The concept of ' $6 R$ ' Methodology}

When looking at the flow of materials in the life cycle of sustainable products, three "patterns" (3R) [11] are noted, which are Reduce, Reuse, and Recycle, which are usually referred to as strategies for treating the product at the end of the life cycle. However, by adopting a more comprehensive and integrated perspective, it is possible to add three more "patents". These are Recover, Redesign, and Remanufacture, where the reduction activity is to reduce activities that seek to simplify the current design of a particular product to facilitate future post-use activities. , As for reuse, it refers to achieving the lowest environmental impact, mainly because it usually involves relatively fewer manufacturing processes [12]. Recycling refers to a series of activities 
that include dismantling, smelting, and separating. Take-back represents the activity of collecting products at the end of the product's life cycle for subsequent use activities. It also refers to the dismantling of specific components of products at the end of their life. Re-design means integration with a reduction in that it involves re-designing the product due to the simplification of post-use processes in the future. Re-manufacturing is similar to manufacturing. However, the difference is that it is not made on virgin materials but on products that are already used. The 6R methodology aims in the product life cycle to reach a state of constant or permanent flow of materials, which in turn means reducing post-use activities [13, 14]. Closed Loop vs. Open Channel Lifecycle Systems. Open Loop Life-cycle Systems Fig 2 shows the closed channel (cradle to cradle) for the life cycle of the product, which is the opposite of the open channel (cradle to grave) (cradle to grave). Products are consumed and are considered obsolete at the end of the product life cycle. According to this scenario, the Material resource, waste output, energy consumed, and the rest of the system emissions are all a function of customer demand. To shift towards a closed channel system, three criteria for sustainable product recycling are required. These criteria are:

1. Reducing the energy and material resources required for the product to perform its primary function to achieve customer demand

2. Optimizing the resources used

3. Reducing or eliminating the adverse effects of waste and emissions

The closed-channel product system must meet two of the aforementioned criteria (i and ii) [15]. In such a manufacturing system, the activities of reuse, recycling, and recycling are the ones that rotate materials in the product system. These activities reduce the requirements for the need to extract new materials to feed the product system, which contributes to reducing the total energy input required and necessarily emissions per unit at production and consumption [16].

\subsection{Product Differentiation}

Product differentiation is a well-defined theoretical concept that is based on two conditions. First, buyers must realize that the goods ("brands") that belong to a product category are close substitutes for each other, but only find relatively poor substitutes with goods outside that category. At the same time, these brands must be sufficiently imperfect substitutes for each seller to see that his brand faces a downward-sloping demand curve. Research on industrial organization often refers to differentiated products, but the empirical correlates of structural differentiation have not received much attention [20].

We first define the conditions that are theoretically sufficient to cause the downward sloping demand curves faced by individual sellers. We then use factor analysis to determine whether these ground rules are attributable to the observed characteristics of the products and the ways that buyers choose. Upon reaching a positive result, we show that price adjustments in a crosssection of industries respond to factors in the way expected from the theoretical foundations of differentiation, as a test of this device for measuring differentiation. At least two models seem to provide conditions sufficient to link downward-sloping demand curves for individual producers to underlying characteristics of demand and technology.[21]

This output set is not attainable, however, if fixed costs or scale economies are present in the production of each distinct bundle. In that case, only some of the many possible bundles are produced. The typical buyer finds no attribute bundle that matches exactly the one he would 
choose under the idealized conditions just defined. Relative prices determine the bundle chosen from among those offered. Although each buyer may make discrete switches between brands as relative prices change, buyers generally differ in their reservation prices for a given configuration. Therefore, downward-sloping demand curves are likely to result when the preferences of individual buyers are aggregated.[22]

The other theoretical model linking downward-sloping demand curves to ambient structural conditions comes from the literature on consumer information and transactions costs [20].

\section{Statistical Analysis and Test Results}

To enhance the theoretical side of the study, the statistical practical aspect was based on the study plan and its hypotheses. The third section was devoted to presenting and discussing the model and research hypotheses.

\subsection{Model Test Results and Hypotheses}

The current paragraph is devoted to presenting and discussing the results of the scheme test and the research hypotheses in terms of the indicators of descriptive and inferential statistical analysis and according to the following paragraphs.

\subsubsection{Test Statistical Analysis of The Descriptive Results of The Research Variables (Statistical Descriptive Analysis)}

Table 1 presents the results of the descriptive statistical indicators tests for the main and secondary research variables in terms of the weight mean (xw) and standard deviation $(\sigma)$, as this paragraph aims to verify the level of response of the research sample to the approved variables and their clarity and dispersion from the arithmetic mean of the measurement tool.

Table 1. Rresults of the descriptive statistical analysis of the research variables.

\begin{tabular}{|c|c|c|c|c|}
\hline $\mathrm{N}$ & Research Variables & $\begin{array}{l}\mathrm{M} \\
\mathrm{e} \\
\mathrm{a} \\
\mathrm{n}\end{array}$ & $\begin{array}{l}\mathrm{s} \\
\mathrm{t} \\
\mathrm{a} \\
\mathrm{n} \\
\mathrm{d} \\
\mathrm{a} \\
\mathrm{r} \\
\mathrm{d} \\
\mathrm{d} \\
\mathrm{e} \\
\mathrm{v} \\
\mathrm{i} \\
\mathrm{a} \\
\mathrm{t} \\
\mathrm{i} \\
\mathrm{o} \\
\mathrm{n}\end{array}$ & $\begin{array}{l}\mathrm{R} \\
\mathrm{e} \\
\mathrm{l} \\
\mathrm{a} \\
\mathrm{t} \\
\mathrm{i} \\
\mathrm{v} \\
\mathrm{e} \\
\mathrm{i} \\
\mathrm{m} \\
\mathrm{p} \\
\mathrm{o} \\
\mathrm{r} \\
\mathrm{t} \\
\mathrm{a} \\
\mathrm{n}\end{array}$ \\
\hline
\end{tabular}




\begin{tabular}{|c|c|c|c|c|}
\hline & & & & $\begin{array}{l}\mathrm{c} \\
\mathrm{e}\end{array}$ \\
\hline 1 & \multicolumn{4}{|c|}{ Design for Sustainability (independent dimensions) } \\
\hline A & $\begin{array}{l}\text { The environmental } \\
\text { dimension of the } \\
\text { design }\end{array}$ & $\begin{array}{l}3 \\
. \\
8 \\
5 \\
1 \\
\end{array}$ & $\begin{array}{l}0 \\
\\
7 \\
2\end{array}$ & 1 \\
\hline B & $\begin{array}{l}\text { Economic dimension } \\
\text { of design }\end{array}$ & $\begin{array}{l}3 \\
2 \\
2 \\
4 \\
2\end{array}$ & $\begin{array}{l}0 \\
6 \\
7\end{array}$ & 3 \\
\hline \multirow[t]{2}{*}{$\mathrm{C}$} & $\begin{array}{l}\text { The social dimension } \\
\text { of design }\end{array}$ & $\begin{array}{l}3 \\
6 \\
6 \\
3 \\
0\end{array}$ & $\begin{array}{l}0 \\
8 \\
8 \\
5\end{array}$ & 2 \\
\hline & General mean & $\begin{array}{l}3 \\
5 \\
5 \\
4 \\
6\end{array}$ & $\begin{array}{l}1 \\
0 \\
2\end{array}$ & - \\
\hline 2 & $\begin{array}{l}\text { Design and } \\
\text { Manufacturing for the } \\
\text { Environment } \\
\text { (Intermediate) }\end{array}$ & $\begin{array}{l}3 \\
. \\
2 \\
2 \\
1\end{array}$ & $\begin{array}{l}0 \\
8 \\
6\end{array}$ & - \\
\hline 3 & \multicolumn{4}{|l|}{ Product competitiveness } \\
\hline & Cost Competitive & $\begin{array}{l}3 \\
6 \\
6 \\
3 \\
0\end{array}$ & $\begin{array}{l}0 \\
6 \\
6 \\
4\end{array}$ & 2 \\
\hline & Quality Competitive & $\begin{array}{l}3 \\
\cdot \\
5 \\
6 \\
0\end{array}$ & $\begin{array}{l}0 \\
8 \\
8 \\
5\end{array}$ & 3 \\
\hline & delivery Competitive & $\begin{array}{l}2 \\
2 \\
4 \\
0\end{array}$ & $\begin{array}{l}0 \\
\dot{4} \\
6\end{array}$ & 4 \\
\hline & Flexibility Competitive & $\begin{array}{l}3 \\
8\end{array}$ & $\begin{array}{l}0 \\
7 \\
7 \\
2\end{array}$ & 1 \\
\hline
\end{tabular}




\begin{tabular}{|c|c|c|}
\hline & $\begin{array}{l}5 \\
1\end{array}$ & \\
\hline General mean & $\begin{array}{l}3 \\
. \\
0 \\
2 \\
2\end{array}$ & $\begin{array}{l}0 \\
7 \\
7 \\
8\end{array}$ \\
\hline
\end{tabular}

statistical program (Spss). $(\mathrm{N}=47)$

As is evident from the results of the descriptive statistical analysis of the research variables, the dimensions of the design methodology for sustainability came according to the relative importance of the research sample in the following order:

The dimension of flexibility competitiveness ranked first in terms of its relative importance with an arithmetic mean of (3.85) and a standard deviation of (0.72). This means that the laboratory adopts standard or standard designs, followed in terms of importance by the dimension of cost competitiveness for a weighted average of (3.630) and with a standard deviation of (3.630) Its value is (0.85), followed by the dimension of quality competitiveness with a weighted mean of (3.56) and a standard deviation (0.04), and finally the dimension of delivery with a weighted mean of (3.24) and a standard deviation of (0.67).

\subsubsection{Results of the Correlation Test (Variables Correlations Test)}

Table 2 presents the results of the test of simple and multiple correlations between independent and dependent research variables within the framework of the intermediate variable represented by design and manufacture for the environment in terms of (Spearman) correlation coefficients for ranks and using the (SPSS) system.

Table 2. Matrix of correlations between research variables.

\begin{tabular}{|c|c|c|c|c|c|c|c|}
\hline & 1 & 2 & 3 & 4 & 5 & 6 & 7 \\
\hline 1 & - & & & & & & \\
\hline 2 & $\begin{array}{l}0 \\
0 \\
7 \\
4 \\
1 \\
*\end{array}$ & - & & & & & \\
\hline 3 & $\begin{array}{l}0 \\
. \\
8 \\
4 \\
2 \\
*\end{array}$ & $\begin{array}{l}0 \\
. \\
7 \\
4 \\
3 \\
*\end{array}$ & - & & & & \\
\hline 4 & 0 & 0 & 0 & - & & & \\
\hline
\end{tabular}




\begin{tabular}{|c|c|c|c|c|c|c|c|}
\hline & $\begin{array}{l}7 \\
8 \\
5 \\
*\end{array}$ & $\begin{array}{l}7 \\
1 \\
6\end{array}$ & $\begin{array}{l}8 \\
9 \\
4 \\
*\end{array}$ & & & & \\
\hline 5 & $\begin{array}{l}0 \\
. \\
4 \\
1 \\
1 \\
*\end{array}$ & $\begin{array}{l}5 \\
2 \\
1\end{array}$ & $\begin{array}{l}4 \\
2 \\
9\end{array}$ & $\begin{array}{l}0 \\
. \\
7 \\
9 \\
6 \\
*\end{array}$ & - & & \\
\hline 6 & $\begin{array}{l}0 \\
\cdot \\
4 \\
6 \\
7 \\
*\end{array}$ & $\begin{array}{l}4 \\
0 \\
4\end{array}$ & $\begin{array}{l}5 \\
6 \\
2 \\
*\end{array}$ & $\begin{array}{l}0 \\
. \\
4 \\
8 \\
5\end{array}$ & $\begin{array}{l}3 \\
9 \\
4 \\
*\end{array}$ & & \\
\hline 7 & & & & & & $\begin{array}{l}0 \\
. \\
4 \\
4 \\
3 \\
* \\
*\end{array}$ & \\
\hline
\end{tabular}

Key to significant test: $* \mathbf{p} \leq \mathbf{0 . 0 5},:^{* *} \mathbf{p} \leq \mathbf{0 . 0 5}$ Source: - The results of the (SPSS)

The results of the correlation matrix will be commented on within the limits of the current research hypotheses, which stipulated the existence of significant correlations between the design for sustainability methodology and the competitiveness of the product in the context of the laboratory's pursuit of sustainability. All dimensions of product competitiveness for products were the most obvious. The correlation relationship between the economic dimensions of design for sustainability with a correlation coefficient of (0.540), followed in terms of strength, the correlation between the social dimension of design for sustainability, and then the relationship with the economic dimension with a correlation coefficient of (0.425) and all of them significantly significant at a confidence level $(0.05)$. The variable design for sustainability also achieved significant correlations, the most obvious of which was the correlation with a psychological one, and its value was $(r=0.460)$ at a significant level of $(0.05)$. The results of the previous analysis verify the validity of the correlation hypotheses adopted in the research.

\subsubsection{Analysis of The Results of The Impact of Design For Sustainability on Product Competitiveness}

The content of this analysis represents the test of the second main research hypothesis that indicates the existence of a significant effect of Design for Sustainability (SPD) in terms of its combined dimensions in achieving product competitiveness. The coefficient of determination 
(2r) of the general model, which indicates that (0.56) of the variance in the competitiveness of the product is explained by the components of the design for sustainability combined, and this is supported by the value of $(\mathrm{F})$ which reached (102.4), which is greater than its tabular value at the level of significance (0.05) and two degrees of freedom ( 4.42).

To explain the relative importance of the partial effects of each component of the design for sustainability in achieving product competitiveness, it is possible to follow the regression coefficients (beta) and the values $(t)$ calculated for each of them. (0.39) of the variance in achieving product competitiveness is supported by the calculated value $(\mathrm{t})$ of (5.42) which is greater than the tabular at the level of significance $(0.05)$, followed by the components (environmental dimension and social dimension) in terms of its regression coefficients of $(0.35$, $0.28,0.25)$. ) respectively and $(\mathrm{t})$ values calculated for each of them compared to the tabular.

It is inferred from the results of the previous analysis that the competitiveness of the product that organizations seek derives its basic components to a large extent from the components of design for sustainability, as the more organizations own this technology, the more they can achieve institutional leadership within their work environment, and thus the second main research hypothesis was achieved.

Table 3. Results of the impact of design for sustainability on product competitiveness.

\begin{tabular}{|l|l|l|l|l|}
\hline \multicolumn{2}{|c|}{$\begin{array}{l}\text { Components of Designing for } \\
\text { Sustainability }\end{array}$} & \\
\hline I & T & T & T & \\
d & h & h & h & \\
e & e & e & e & F \\
p & e & E & s & \\
e & n & c & o & \\
n & v & o & c & \\
d & i & n & i & \\
e & r & o & a & \\
n & o & m & l & \\
t & n & d & \\
v & m & c & i & \\
a & e & D & m & \\
r & n & i & e & \\
i & t & m & n & \\
a & a & e & s & \\
b & l & n & i & \\
l & d & s & o & \\
e & i & i & n & \\
& m & e & o & \\
& e & n & f & \\
& s & f & \\
\hline
\end{tabular}




\begin{tabular}{|c|c|c|c|c|c|c|}
\hline & & \begin{tabular}{|l}
$\mathrm{i}$ \\
$\mathrm{o}$ \\
$\mathrm{n}$ \\
$\mathrm{o}$ \\
$\mathrm{f}$ \\
$\mathrm{t}$ \\
$\mathrm{h}$ \\
$\mathrm{e}$ \\
$\mathrm{d}$ \\
$\mathrm{e}$ \\
$\mathrm{s}$ \\
$\mathrm{i}$ \\
$\mathrm{g}$ \\
$\mathrm{n}$ \\
$\mathrm{f}$ \\
$\mathrm{o}$ \\
$\mathrm{r}$ \\
$\mathrm{s}$ \\
$\mathrm{u}$ \\
$\mathrm{s}$ \\
$\mathrm{t}$ \\
$\mathrm{a}$ \\
$\mathrm{i}$ \\
$\mathrm{n}$ \\
$\mathrm{a}$ \\
$\mathrm{b}$ \\
$\mathrm{i}$ \\
$\mathrm{l}$ \\
$\mathrm{i}$ \\
$\mathrm{t}$ \\
$\mathrm{y}$
\end{tabular} & $\begin{array}{l}\mathrm{D} \\
\mathrm{e} \\
\mathrm{s} \\
\mathrm{i} \\
\mathrm{g} \\
\mathrm{n} \\
\mathrm{f} \\
\mathrm{o} \\
\mathrm{r} \\
\mathrm{S} \\
\mathrm{u} \\
\mathrm{s} \\
\mathrm{t} \\
\mathrm{a} \\
\mathrm{i} \\
\mathrm{n} \\
\mathrm{a} \\
\mathrm{b} \\
\mathrm{i} \\
\mathrm{l} \\
\mathrm{i} \\
\mathrm{t} \\
\mathrm{y}\end{array}$ & $\begin{array}{l}\mathrm{s} \\
\mathrm{i} \\
\mathrm{g} \\
\mathrm{n} \\
\mathrm{i} \\
\mathrm{n} \\
\mathrm{g} \\
\mathrm{f} \\
\mathrm{o} \\
\mathrm{r} \\
\mathrm{s} \\
\mathrm{u} \\
\mathrm{s} \\
\mathrm{t} \\
\mathrm{a} \\
\mathrm{i} \\
\mathrm{n} \\
\mathrm{a} \\
\mathrm{b} \\
\mathrm{i} \\
\mathrm{l} \\
\mathrm{i} \\
\mathrm{t} \\
\mathrm{y}\end{array}$ & & \\
\hline $\begin{array}{l}\mathrm{P} \\
\mathrm{r} \\
\mathrm{o} \\
\mathrm{d} \\
\mathrm{u} \\
\mathrm{c} \\
\mathrm{t} \\
\mathrm{c} \\
\mathrm{o} \\
\mathrm{m}\end{array}$ & B & $\begin{array}{l}0 \\
. \\
2 \\
6\end{array}$ & 0 & $\begin{array}{l}0 \\
. \\
2 \\
8\end{array}$ & $\begin{array}{l}0 \\
. \\
5 \\
6\end{array}$ & 4 \\
\hline
\end{tabular}




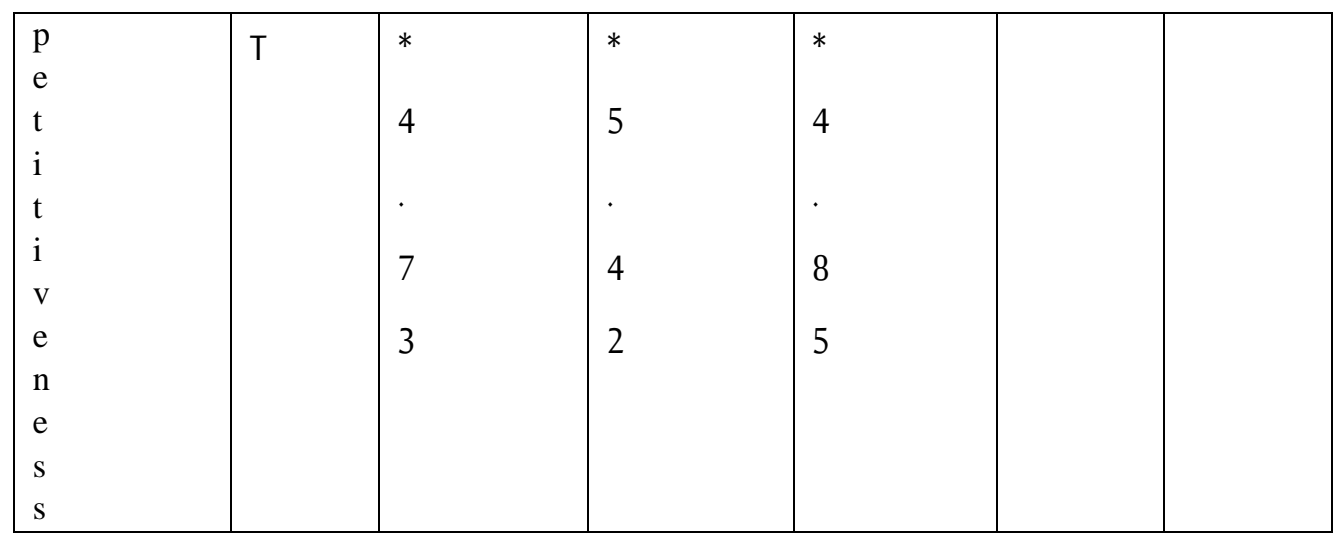

Prepare the table in light of the results of the Computer d.f $4,42<0.05 * \mathrm{~N}=3$

\section{Conclusions and Recommendations}

The research reached several conclusions, the most important of which are:

1. The dimensions of design for sustainability did not achieve real substantive results in the researched laboratory in terms of many of the standards adopted in the research, as the most important dimension of the dimensions of design for sustainability, which received the attention of the research sample, was the economic dimension of product sustainability.

2. In the same direction, the product competitiveness indicators of the laboratory products did not exceed the standard limits of the scale adopted in the research by much. This conclusion is supported by the fact that the products of the laboratory lag behind in the standards of sustainability compared to similar products in international companies.

3. The results of the statistical analysis showed the existence of a significant correlation between the level of implementation of the design methodology for sustainability and the competitiveness of the product for the products of the laboratory in question.

4. The results of the statistical analysis proved that the Design for Sustainability methodology can explain the variation in product competitiveness indicators for the factory products, and its impact increases with the presence of the design variable for the environment as an intermediate variable.

5. The results of many field indicators showed that all the laboratory practices examined need further development and modernization to take advantage of the design for sustainability and design for the environment methodology to support the competitiveness of their products.

The most important recommendations reached by the research: 
1. The necessity of activating the laboratory practices of the design methodology for sustainability, as it is one of the contemporary entrances to improve the competitiveness of products, a strategy for survival, and improve profitability.

2. Develop and update the capabilities of the factory workers to adopt the design methodology for the environment as a vital approach to improve product competitiveness indicators for competing products in the market.

3. Activate and update manufacturing and production technology in the factory to meet the requirements of the design methodology for sustainability and design for the environment to improve the competitiveness of the product.

4. Activate integration and coordination mechanisms between production and service departments to improve their ability to optimize the dissemination and exchange of information related to the successful implementation of the Design for Sustainability methodology.

5. The need for the laboratory management to pay attention to the availability of infrastructure and the material and human requirements to improve the indicators of the sustainability of the products and processes of the laboratory.

\section{References}

[1] Bhamra, T., \& Lofthouse, V. (2016). Design for sustainability: a practical approach. Routledge.

[2] Ceschin, F., \& Gaziulusoy, I. (2016). Evolution of design for sustainability: From product design to design for system innovations and transitions. Design studies, 47, 118-163.

[3] Ceschin, F., \& Gaziulusoy, İ. (2019). Design for Sustainability (Open Access): A Multi-level Framework from Products to Socio-technical Systems. Routledge.

[4] Yıldız, S., Kıvrak, S., Gültekin, A. B., \& Arslan, G. (2020). Built environment design-social sustainability relation in urban renewal. Sustainable Cities and Society, 60, 102173.

[5] Yıldız, S., Kıvrak, S., Gültekin, A. B., \& Arslan, G. (2020). Built environment design-social sustainability relation in urban renewal. Sustainable Cities and Society, 60, 102173.

[6] Shabbir, M. S., Mahmood, A., Setiawan, R., Nasirin, C., Rusdiyanto, R., Gazali, G., ... \& Batool, F. (2021). Closed-loop supply chain network design with sustainability and resiliency criteria. Environmental Science and Pollution Research, 1-16.

[7] Changede, S., Thomas, L., \& Walker, S. (2021, March). Learning from Traditional Practices and Products in India to inform Design for Sustainability. In Fifteenth International Conference on Design Principles and Practices.

[8] Pan, S. L., Li, M., Pee, L. G., \& Sandeep, M. S. (2021). Sustainability design principles for a wildlife management analytics system: Action design research. European Journal of Information Systems, 30(4), 452-473.

[9] Xia, B., Xiao, J., Ding, T., \& Zhang, K. (2021). Probabilistic sustainability design of structural concrete components under climate change. Structural Safety, 92, 102103.

[10] Fonseca, J. D., Commenge, J. M., Camargo, M., Falk, L., \& Gil, I. D. (2021). Multi-criteria optimization for the design and operation of distributed energy systems considering sustainability dimensions. Energy, 214, 118989.

[11] Schwaninger, M. (2018). Systemic design for sustainability. Sustainability Science, 13(5), 12251234.

[12] Park, H. S., Hwang, J. W., \& Oh, B. K. (2018). Integrated analysis model for assessing CO2 emissions, seismic performance, and costs of buildings through performance-based optimal seismic design with sustainability. Energy and Buildings, 158, 761-775.

[13] Siu, K. W. M., \& Xiao, J. X. (2020). Public facility design for sustainability: Participatory action research on household recycling in Hong Kong. Action Research, 18(4), 448-468. 
[14] Mihelcic, J. R., \& Zimmerman, J. B. (2021). Environmental engineering: Fundamentals, sustainability, design. John wiley \& sons.

[15] Seidel, S., Chandra Kruse, L., Székely, N., Gau, M., \& Stieger, D. (2018). Design principles for sensemaking support systems in environmental sustainability transformations. European Journal of Information Systems, 27(2), 221-247.

[16] Pan, S. L., Li, M., Pee, L. G., \& Sandeep, M. S. (2021). Sustainability design principles for a wildlife management analytics system: Action design research. European Journal of Information Systems, 30(4), 452-473.

[17] Seidel, S., Chandra Kruse, L., Székely, N., Gau, M., \& Stieger, D. (2018). Design principles for sensemaking support systems in environmental sustainability transformations. European Journal of Information Systems, 27(2), 221-247.

[18] Ebenezer, O. (2019). Graphic Design Principles and Theories Application in Rendering Aesthetic and Functional Installations for Improved Environmental Sustainability and Development. International Journal of Engineering and Manufacturing, 9(1), 21.

[19] Cortina, J.M. (1993). "What is coefficient alpha? An examination of theory and applications". Journal of Applied Psychology. 78: 98-104.

[20] Chen, J., Wang, X., \& Chu, Z. (2020). Capacity sharing, product differentiation and welfare. Economic research-Ekonomska istraživanja, 33(1), 107-123.

[21] ROSEN, S., 1974, 'Hedonic Prices and Implicit Markets: Product Differentiation in Pure Competition', Journal of Political Economy, 82 (January/February), pp. 34-55.

[22]ARCHIBALDG, . C., EATON, B. C. and LIPSEY,R . G., 1983, 'Address Models of Value Theory', Institute for Economic Research, Queen's University, Discussion PaperNo.495 